\title{
Documentação linguística das zonas raianas de Portugal e Espanha: o projeto Frontespo, com análise do caso da Beira Baixa / Extremadura espanhola
}

\author{
Fernando Brissos ${ }^{1}$ \\ Universidade de Lisboa, Faculdade de Letras, Centro de Linguística
}

\begin{abstract}
:
This paper takes on two main objectives. The first is to present and depict the project Frontespo - Frontera hispano-portuguesa: documentación lingüística y bibliográfica [Spanish-Portuguese frontier: linguistic and bibliographic documentation], which aims at producing a comprehensive linguistic documentation of the frontier area between Portugal and Spain. The second objective is to study the stressed vowel systems of a specific border area located in the central interior part of Portugal, which, despite not having been subject to a detailed depiction up to this day, is decisive in understanding the constitution of Portuguese central-southern dialects as a whole, as recent studies have shown. The results are clear in (i) allowing for the description of the area's vowel systems and (ii) improving our view on the history of central-southern Portuguese. This study therefore exemplifies the type of linguistic approach that a project like Frontespo allows for and, more importantly, the need for new, comprehensive language documentation projects in Portugal.
\end{abstract}

Keywords: Language documentation, Spanish-Portuguese border, central-southern Portuguese vowel system, central interior Portuguese dialects.

Palavras-chave: Documentação linguística, fronteira Portugal-Espanha, sistema vocálico do centro-sul português, dialetos do centro-interior português.

\section{Documentação linguística das zonas raianas de Portugal e Espanha: o projeto} Frontespo $^{2}$

O Frontespo - Frontera hispano-portuguesa: documentación linguística y bibliográfica

3 é um projeto pioneiro de documentação linguística da zona fronteiriça Portugal-Espanha, área cujo interesse especial advém de oito razões fundamentais:

(i) trata-se de uma das mais antigas e estáveis fronteiras políticas da história,

\footnotetext{
${ }^{1}$ Financiado pelo projeto Frontespo - Frontera hispano-portuguesa: documentación linguística y bibliográfica (Governo espanhol, Ministerio de Economía y Competitividad, ref. FFI2014-52156-R; triénio 2015-2017). $O$ Investigador Responsável é Xosé Afonso Álvarez Perez, da Universidad de Alcalá de Henares (Espanha).

${ }^{2}$ Seguiremos nas transcrições fonéticas a notação do Alfabeto Fonético Internacional (versão revista de 2005).

${ }^{3}$ Página web do projeto: http://www.frontespo.org/.
} 
(ii) que tem sido ao longo do tempo, contudo, uma região de intenso intercâmbio económico e cultural, tanto temporário (trabalho sazonal, contrabando, festas, etc.) como permanente (casamentos mistos, emigração, deserção, fuga à justiça, etc.);

(iii) tem sido, também, uma região com um forte sentido identitário, em que o contacto com os povos vizinhos do outro lado da fronteira é frequentemente mais intenso do que com os povos das principais zonas urbanas dos respetivos países; daí, p. ex., os habitantes da fronteira em geral terem um gentílico comum: (ar)raianos / rayanos. Pode de facto falar-se da fronteira como uma entidade (sempre se pôde, aliás: cf. Amante, 2010), ao jeito de uma zona cinzenta que separa as cores nítidas formadas pelos elementos centrais de Portugal e Espanha;

(iv) a situação da fronteira sofreu recentemente desenvolvimentos significativos, devido sobretudo à criação do chamado Espaço Schengen (livre circulação nas fronteiras) e à desertificação das partes interiores tanto de Portugal como de Espanha (processo muito intensivo nas últimas décadas, acompanhando o decréscimo acentuado da importância do setor primário na estrutura económica de ambos os países). A influência radical destes dois aspetos no modo de vida das populações vê-se a olho nu aumentar de ano para ano - tenha-se presente, p. ex., que o contrabando, instrumento económico fundamental da raia ao longo da história, já não é possível, pois as fronteiras caíram. A documentação linguística da região torna-se, portanto, uma urgência neste momento,

(v) tal como também se torna pelo mais geral processo de desaparecimento do modo de vida tradicional, que tem afetado países do sul da Europa como Portugal e Espanha de forma extremamente incisiva nas últimas décadas;

(vi) e não deixa igualmente de ser uma urgência pelo também geral processo de forte expansão das variedades standard de português e espanhol recentemente, devido, principalmente, ao aumento drástico da escolarização e à difusão generalizada dos mass media. Note-se por exemplo que são menos de $5 \%$ os jovens que, na Terra de Miranda, sabem falar o mirandês ou, mais a Sul, preferem o português ao espanhol na região de Olivença (Merlan, 2009 e Matias, 2001, respetivamente; apud Álvarez Perez, 2015). As variedades linguísticas (línguas ou dialetos) não-padrão estão sob forte pressão em 
ambos os países e a sua documentação exaustiva não pode, também por esta razão, ser adiada;

(vii) apesar da sua estabilidade, os limites estatais que separam Portugal e Espanha apresentam um número significativo de discrepâncias com as fronteiras linguísticas reais. O mirandês, dialeto da antiga língua leonesa falada do lado de lá da fronteira, é talvez o exemplo mais significativo, mas muitos outros existem (veja-se p. ex. Carrasco, 1996-1997 a respeito da Extremadura espanhola, que confina com o centro-interior português). A necessidade de uma cartografia linguística detalhada da fronteira Portugal-Espanha, que se possa confrontar com a geografia política, torna-se assim evidente;

(viii) há a considerar por último um aspeto que, sendo menos intuitivo, não deixa, porém, de ter a maior importância no âmbito linguístico: as variedades standard tanto do português como do espanhol e, bem assim, as suas áreas urbanas mais importantes (onde está a maioria da população e de onde provém a inovação linguística mais significativa) estão localizadas longe da fronteira de ambos os estados. Ora, isso faz com que os dialetos raianos sejam propícios à conservação de estados de língua arcaizantes e, por isso, sejam de particular interesse para a reconstrução histórica de ambas as línguas.

Apesar de o interesse linguístico da fronteira Portugal-Espanha ser claro, ainda não existe uma tradição significativa de estudo da região. Existem trabalhos soltos, como Santos (1967), Maia (1977), Matias (1984), Boller (1995), Beswick (2005) ou os vários estudos de Christina Ossenkop (cf. Ossenkop, 2013); e existem também alguns trabalhos de síntese, como Maia (2001), Andrés Díaz (2007) e Gargallo Gil (2011). Mas a fronteira Portugal-Espanha continua a ser um tema menor nos estudos linguísticos, porque falta uma visão detalhada e de profundidade sobre o assunto, lacuna que, apesar de tudo, não de deixa de ser natural, tendo em conta outra lacuna mais geral: a falta de dados primários (gravações, transcrições, materiais de fala dos pontos inquiridos: em suma, dados não digeridos) que afeta tradicionalmente a dialetologia ibérica, exponencialmente a portuguesa. O Frontespo toma precisamente como objetivo fundamental colmatar essas duas lacunas sequenciais, ou seja, proceder à «documentação linguística exaustiva da franja fronteiriça entre Espanha e Portugal» (site do projeto, separador «Introdução»). 
O Frontespo é composto por três núcleos. Em primeiro lugar, a recolha de corpus oral da raia Portugal-Espanha, que é a base do projeto. Na sua primeira fase, já concluída, esse corpus é composto por dez zonas-alvo - cf. Anexo, mapa $1-$, em que todas as províncias espanholas e todos os distritos portugueses são compreendidos (com exceção do distrito de Braga, que tem uma parcela exígua de território na fronteira). Em cada zona, um mínimo de 4 localidades $=2$ em Portugal +2 em Espanha foram inquiridas, sendo que nenhuma dessas localidades dista a mais de $15 \mathrm{kms}$ da fronteira política (em linha reta). A seleção das localidades inquiridas obedeceu ainda a outro critério: em cada zona, uma das localidades portuguesas e uma das espanholas já terem sido alvo de algum tipo de trabalho linguístico (ponto de inquérito de atlas linguístico, objeto de estudo em monografia, etc.), de forma a possibilitar a comparação entre estados de língua diferentes.

Em cada localidade foram inquiridos pelo menos três informantes, com diversidade de género (um homem e duas mulheres ou vice-versa) e etária, dividida em três escalões: um informante com menos de 50 anos, outro entre 50 e 75 e outro com mais de 75 . Do mesmo modo, em todas as localidades foi aplicado um questionário linguístico-etnográfico com 163 perguntas-base e apêndices sociolinguísticos, sujeito a três eixos temáticos: campos semânticos da vida tradicional (vida rural, ofícios tradicionais, flora e fauna, etc.), informação etnográfica sobre a vida na raia (contrabando, relações entre povos vizinhos, etc.) e juízos linguísticos do informante (dialeto da terra, das terras vizinhas, diferenças linguísticas entre gerações, diferenças entre os dois lados da fronteira, etc.). Todas as gravações compreendem não só fala semidirigida como também fala espontânea, de forma a obter discurso dialetologicamente inquestionável. As entrevistas são gravadas em aúdio e, sempre que o informante também o permite - o que aconteceu, até agora, na grande maioria dos casos - em vídeo. A gravação visual não deixa de ser importante, pois permite incorporar um conjunto de informação que pode ser preciosa: elementos paralinguísticos gerais, explicitação de respostas, controlo, da parte do investigador, da postura e produção de fala do informante (com vista à análise acústica da fala), etc..

Das dez zonas inquiridas resultaram 57 localidades e 238 informantes em 178 entrevistas com perto de 300 horas totais de gravação.

O segundo núcleo do projeto é a constituição, a partir do seu site, de um repositório online, em regime de acesso livre, de materiais da fronteira. Frisamos o acesso totalmente livre, 
gratuito e fácil, necessidade que o projeto entende como vital na ciência contemporânea feita com base em dinheiros públicos. O repositório é composto por duas secções:

a) Gravações dialetais: é editado, transcrito e publicado o corpus oral recolhido, mas também qualquer material similar cedido por terceiros (salvaguardando, naturalmente, as autorias).

b) Outro material: é catalogado detalhadamente e, quando de interesse (e.g. está inédito ou inacessível), reproduzido qualquer outro material relevante (livros, textos, mapas, documentários audiovisuais, etc.) recolhido dentro ou fora do projeto; e é disponibilizada uma seleção de hiperligações sobre a fronteira nos seus mais variados âmbitos, joeirando a quantidade enorme e difusa de sites de internet que podem ter conteúdos de interesse.

O objetivo por trás deste núcleo é a constituição de um portal da fronteira PortugalEspanha onde a informação necessária para o seu estudo científico e académico ou, tão-só, para o seu conhecimento genérico esteja centralizada. Assim o portal procura, por um lado, disponibilizar os novos materiais que vão surgindo e, por outro, sistematizar e colocar em fácil acesso os que já existem (e estão normalmente dispersos em arquivos ou bibliotecas de vária natureza). Será pois um importante instrumento de visibilidade para materiais - académicos ou não académicos, em texto ou em som/vídeo, etc. — sobre a fronteira que o Frontespo assume declaradamente, enfatizando a sua total disponibilidade para proceder a essa divulgação e o seu total compromisso com a salvaguarda da autoria dos trabalhos cedidos, seja de que tipo forem.

O terceiro e último núcleo do projeto é formado pela análise linguística dos materiais recolhidos, ou seja, a concretização do objetivo assumido pelo Frontespo de se constituir não só como um projeto de documentação linguística strictu sensu mas, também, de avanço prático dos conhecimentos sobre o assunto documentado.

Outras componentes do projeto são:

a) $\mathrm{O}$ estabelecimento de uma bibliografia multidisciplinar da fronteira PortugalEspanha, tomando como base o repertório de Ferreira \& González Salgado (2015), que será melhorado por via: da criação de uma base de dados temática com gestão informatizada dos materiais e disponibilização online no site do Frontespo (o repertório citado é um volume no sentido clássico, i.e. de consulta página a página); da consideração de toda a fronteira Portugal-Espanha (e não apenas a fronteira 
vertical); da inclusão de todos os ramos do conhecimento; da delimitação geográfica precisa de todos os registos bibliográficos; e do fornecimento de metadados descritivos.

b) A localização e edição de textos históricos da fronteira, i.e. textos de fases anteriores do português/espanhol que tenham sido produzidos na raia ou que lhe digam respeito. Esses textos proporcionam uma comparação diacrónica valiosa em áreas linguisticamente conservadoras, para além de que permitem aumentar o tão deficitário conjunto de textos ibéricos (sobretudo portugueses) regionais antigos publicados até hoje.

c) A criação do Tesoro léxico de la frontera hispano-portuguesa, que, «promovido pelo Doutor José Antonio González Salgado, compila o vocabulário compartilhado por um e outro lado da fronteira Portugal-Espanha. Deixando de lado o fundo lexical comum e os empréstimos estendidos a todo o território, o Tesoro é um dicionário que compila o léxico que une os dois lados da franja fronteiriça e que, por outro lado, separa a fronteira Portugal-Espanha do resto de ambos os países» (site do projeto, separador «Introdução»). É, portanto, um reflexo da necessidade da abordagem à raia como uma entidade nos estudos linguísticos.

Veremos agora um exemplo de aplicação prática dos dados do Frontespo, em que, fazendo uso do significativo apport diacrónico dos dados dialetais recolhidos pelo projeto, é possível melhorar o entendimento de uma questão importante que pendia há bastante tempo na dialetologia portuguesa.

\section{Para a origem do vocalismo tónico do centro-interior português e dos dialetos meridionais portugueses}

\subsection{Introdução e problema}

No centro-interior português está uma variedade dialetal destacada, a que Lindley Cintra, na proposta de classificação dos dialetos portugueses utilizada de forma praticamente unânime desde a sua primeira publicação, chamou «variedade da Beira Baixa e Alto Alentejo, correspondendo a uma região que tem como principais núcleos urbanos Castelo Branco e Portalegre e cujos dialectos se caracterizam por uma profunda alteração de timbre de todo o sistema vocálico, principalmente do tónico» (Cintra, 1983a: 155). Antes de Cintra, também a maioria dos outros autores que se ocuparam da classificação dos dialetos portugueses registou 
a existência de uma variedade dialetal especialmente diferenciada na região: assim estão Vasconcelos (1893) (mas não já 1901 e 1929, textos em que o autor aprofundou o caráter essencialmente geográfico-administrativo que sempre utilizou na sua visão do sistema dialetal português) e Boléo \& Silva (1974); na restante proposta de classificação dialetal do português, Vázquez Cuesta \& Luz (1980) não destacam a variedade, mas as autoras seguem uma visão declaradamente macro, limitando-se a dividir os dialetos portugueses em três grupos: norte, centro e sul.

Sendo portanto pacífica a sua identificação, a delimitação da variedade feita por Cintra também não foi ainda revista (cf. Anexo, mapa 2), mas a caracterização foi sofrendo alterações de pormenor. A versão mais atual é de Segura (2013: 102-103), que define assim os seus «traços mais salientes»: ${ }^{4}$

(i) Palatalização de /u/ [do português padrão] em vários graus, a que correspondem as notações [y], o grau mais elevado, e [u], como nos exemplos de (1):

(1-a) [týd] tudo, [krý] cru, [nýke] nuca, [lúe] lua, [

(1-b) [sṹm] sumo, [3ứki] junco, [nû́ke] nunca

(ii) palatalização condicionada de /a/ acentuado em [ع], em determinados contextos; trata-se de um fenómeno de harmonização vocálica que ocorre quando na sílaba

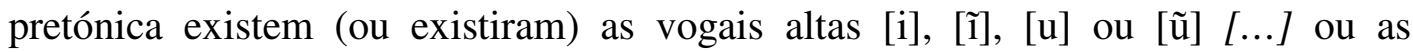
semivogais correspondentes [j] e [w], como se apresenta nos exemplos (2) e (3); chama-se a atenção para os exemplos de (2c) e de (3c), que mostram a alteração de timbre das vogais tónicas pela influência das semivogais dos ditongos [ej] e [ow], alteração que ocorre mesmo em casos em que os ditongos tenham monotongado (no caso do ditongo [ow], o resultado da monotongação é a vogal [ø], como é referido em (iii)):

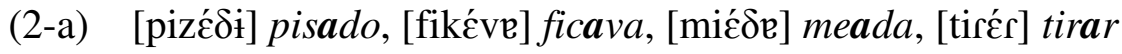

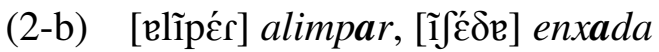

(2-c) [sef́́s] ceifar, [detér] deitar

\footnotetext{
${ }^{4}$ Adaptamos a numeração dos exemplos; mantemos a notação fonética da autora, que segue o Alfabeto Fonético Internacional (Raposo et al., 2013: XXXIX-XLIII).
} 
(3-a) [kurćl] curral, [punćdi] punhado

(3-b) [eउũtér] ajuntar

(3-c) [røßér] roubar, [pøzér] pousar

(iii) palatalização da vogal proveniente da monotongação do antigo ditongo [ow] em [ø], como se mostra nos exemplos (4) e também em (3-c):

(4-a) [rǿpe] roupa, [tǿr] touro, [mǿte] mouta

(4-b) [pøzí] pousio, [øvír] ouvir

(iv) arredondamento e abaixamento da vogal [e] em [œ], como em (5):

(5) [kuzór] cozer, [sóft] cesto, [pól] pelo

(v) elisão da vogal final não acentuada [u], grafada $<0>$, ou a sua realização como [i], como mostram alguns dos exemplos já apresentados e ainda os de (6):

(6-a) [bałdí] baldio [...]

(6-b) [kóp] copo

(6-c) [trốki] tronco

Ora, a existência deste conjunto de fenómenos (cujo inventário tem sido no fundamental, como se disse, pacífico há muito) no centro-interior português coloca questões decisivas para a formação dos dialetos portugueses meridionais, pela seguinte ordem de razões.

a) O centro-interior fica com um sistema vocálico tónico que é extremamente destacado do sistema padrão e que

b) encontra paralelos importantes em duas regiões distantes: o ocidente algarvio, onde também existe a palatalização de u e o enfraquecimento de [u] átono final (cf. Segura, 2013: 104-105 e o mapa 2 adiante: está precisamente no ocidente algarvio mais uma das três variedades dialetais especialmente idiossincráticas indicadas por Cintra, a que o autor chama «regiões subdialectais com características peculiares bem diferenciadas»); e os dialetos insulares, exponencialmente o de S. Miguel dos Açores (a variedade dialetal mais destacada do sistema português), onde também existem os dois traços acabados de referir e ainda os indicados em (iii) e (iv) da numeração de Segura (cf. Segura, 2013: 105-116).

c) Paralelos esses que são ainda maiores do que os estudos de conjunto como Segura (2013) ou Cintra (1983a) dão a entender. De facto, se descermos ao nível dos trabalhos que se ocupam de localidades ou falares específicos — ou seja, estudos de caso - , 
vemos frequentemente indicados fenómenos que denotam mais semelhanças do centrointerior com o ocidente algarvio e S. Miguel do que as consagradas nos estudos de conjunto, nomeadamente subfenómenos integrantes do deslocamento em cadeia do sistema vocálico tónico que caracteriza essas duas variedades. Sucintamente, o deslocamento em cadeia referido compreende: ${ }^{5}$ 1) a abertura de /i/ (entenda-se /i/ do português padrão) em /e/ ou /I/, como em [ge'lene] galinha, ['rık] rico; 2) a abertura de /e/ em /ع/, no ocidente algarvio (e.g. [ke'bese] cabeça, [di'zer] dizer), ou a velarização/arredondamento, em S. Miguel (e.g. [ke'b3se] cabeça, [di'zœr] dizer); 3) a abertura de /E/ em /æ/, como em ['ærve] erva, ['pædre] pedra; 4) a velarização de /a/, como em ['mpr] mar, ['npte] nata; 5) o fechamento de /o/ em /o/ ou /o/ (este raro), como em ['ơbre]/['obre] obra, ['kopp]/['kop] copo; 6) o fechamento de /o/ em /u/, que parece ocorrer apenas de forma regular em S. Miguel, apesar de vários relatos da existência do fenómeno no ocidente algarvio (de que Cintra, 1983a: 158 faz eco, considerando-o característico da região); e.g. [si'nur] senhor, ['nuf] novo; e 7) a já referida palatalização $\mathrm{de} / \mathrm{u} / \mathrm{em} / \mathrm{y} / \mathrm{ou} / \mathrm{u} / .^{6}$

Ora, todos ou quase todos estes fenómenos - e não só a velarização ou arredondamento de /e/ (número 2) e a palatalização de /u/ (número 6), os consagrados na tradição dos estudos de conjunto - ocorrem mais ou menos dispersos pelo centro-interior português, como mostram os dados de Brissos (2012) e os estudos de caso reunidos pelo autor (cf. Brissos, 2012: 486-487) e a análise detalhada da literatura feita por Brissos \& Saramago (2014). Se representarmos esquematicamente esse conjunto de fenómenos tal como existe na região, temos o seguinte esquema, em que podemos facilmente perceber o porquê de se tratar de um movimento em cadeia:

\footnotetext{
${ }^{5}$ Caracterizações completas, incluindo contextualizações de alguns fenómenos, encontram-se em Segura (2013: 104-105), para o barlavento algarvio, e Segura (2013: 111-123), para a variedade micaelense.

${ }^{6} \mathrm{O}$ resultado são sistemas fonológicos radicalmente diferentes do sistema padrão, e por isso extremamente distintivos, tendo como consequência o lugar especial que os estudos de classificação dialetal lhes reconhecem no panorama português (destaque, aliás, também românico).
} 


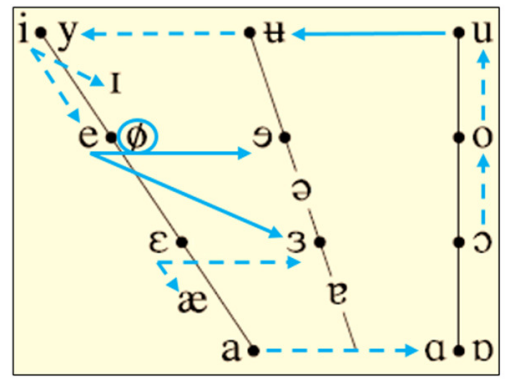

Quadro 1 - Deslocamento em cadeia do vocalismo tónico do centro-interior

Legenda: Com tracejado, os fenómenos que não têm sido considerados transversais ao centrointerior pelos estudos de conjunto (e.g. Segura, 2013: 102-103, passo citado acima); com traço contínuo, os traços que têm sido considerados identificadores de primeira ordem da região.

Está representada não só a velarização (ou centralização) de /e/ como a de /ع/, que também existe no centro-interior (Cintra, 1983a: 156; Brissos, 2012: 61); essa realização, e não propriamente uma vogal palatal arredondada, como [œ], é a realização regular na região (Brissos, 2012: 59; Brissos, 2014: 86 ss.). Igualmente está representada a realização palatalizada/arredondada do antigo ditongo [oun] em [ø] (Segura, 2013: 102-103, passo citado acima, item (iii)), que não se enquadra no movimento das vogais simples mas também contribui para a distintividade do vocalismo da região. A monotongação do antigo ditongo [ei], que é geral na região, gera a qualidade vocálica [e], ou seja, uma vogal não velarizada/centralizada.

d) Este facto agrava substancialmente o mistério das semelhanças entre regiões que, por um lado, são tão destacadas no sistema dialetal português, mas, por outro, estão afastadas; por outras palavras, a proximidade linguística, extremamente sugestiva em variedades muito idiossincráticas, choca de frente com o afastamento geográfico. Divergência essa que, por sua vez, tem implicações decisivas na explicação da origem dessas variedades, e contribuiu certamente para a formulação da teoria de Cintra: os caracteres salientes da variedade do centro-interior dever-se-iam a colonização francesa medieval das ordens militares que se ocuparam da Reconquista Cristã na região e que, depois, teriam colonizado o ocidente algarvio (aproveitando para a discussão, naturalmente, a semelhança evidente entre o vocalismo do centro-interior e o francês; vejam-se a esse respeito Cintra, 1983b: 53-54; Segura, 1987: 270; Brissos, 2012: 494495; Segura, 2013: 103-104). Teríamos aqui, portanto, uma filiação genética do barlavento do Algarve no centro-interior; a variedade micaelense, por seu lado, seria um eixo lateral e posterior, um resultado da colonização portuguesa dos Açores, com influências dos dois grupos de dialetos. 
A hipótese de Cintra seguiu-se a duas ordens de teorias: a visão, defendida já desde os primeiros linguistas (como Ascoli, Schuchardt, Menéndez Pidal), embora nunca de forma unânime, de que pelo menos alguns dos caracteres em questão se deveriam a substrato céltico, e a teoria, menos adotada, do desenvolvimento puramente estrutural dos fenómenos, i.e. a sua explicação com base apenas em fatores internos ao sistema (cf. as sistematizações de Brissos, 2012: 26 e Segura, 1987: 263 ss.).

e) Estudos recentes, porém, trouxeram à luz dados que mostram que as variedades do centro-interior e do ocidente do Algarve são meras exponenciações ou maximizações de tendências mais ou menos gerais dos dialetos portugueses do centro-sul, ou seja, o que parece ser uma falha linguística correspondente a uma falha ou intervalo geográfico entre o centro-interior e o sudoeste é, na verdade, apenas aparente e representa um fundo latente comum a todo o centro-sul. Como Brissos (2015: 1020-1021) refere, aquelas variedades «não são factos dialectais isolados do restante conjunto centro-sulista do país, mas sim exponenciações de tendências superiores do Centro-Sul. [...] não são exactamente "regiões subdialectais com características peculiares bem diferenciadas" (classificação [...] de Cintra); são [...] regiões extremas de processos mais ou menos gerais» (itálico do autor). Trata-se de constatações que nos levarão a reformular a nossa visão da origem das variedades em causa mas também do próprio português centromeridional, pois ele opõe-se ainda mais do que se pensava ao português setentrional, de onde a língua é originária, e ao próprio português padrão, localizado no centro-sul já desde o final da Idade Média (Teyssier, 2001: 35; Castro, 2006: 150-155). No fundo, constatamos que o português centro-meridional é ainda mais uno do que tradicionalmente se pensa, unidade essa que provoca um conflito considerável com o norte e com a própria norma, pois não podemos já considerar os dois cantos que o centro-interior e o ocidente algarvio formam no todo do centro-sul como factos dialetais 
desligados do conjunto, como verdadeiras idiossincrasias. ${ }^{7}$

Os estudos referidos que suportam essa constatação de que o intervalo entre a variedade do centro-interior e a do ocidente algarvio é muito mais aparente e geográfico do que real e linguístico são de dois tipos. Em primeiro lugar, estudos de base fonética que incidem sobre os sistemas vocálicos dos dialetos portugueses a sul do Tejo: o estudo de base acústica de Brissos (2014), cujos resultados principais são apresentados adiante nos mapas 3 e 4 do Anexo, e que mostra fenómenos que tradicionalmente são tidos como exclusivos das duas variedades referidas dispersos pelo centro-sul ${ }^{8}$; e o estudo de Brissos \& Saramago (2014), que comprova, a partir de uma análise exaustiva dos estudos de caso da mesma área abordada por Brissos (2014), as conclusões desse trabalho; estudos de caso esses que, note-se, têm uma base exclusivamente percetiva, pois a dialetologia acústica ainda tem uma tradição diminuta em Portugal (tal como, de resto, na maior parte dos países).

Em segundo lugar, a abordagem holística de Brissos (2015), que analisa dialetometricamente um corpus exaustivo de fenómenos fonológicos e morfológicos/morfossintáticos do centro-sul (mesma área e mesmos pontos de inquérito de Brissos, 2014) e encontra resultados que mostram, mais uma vez, que o centro-sul depende de um fundo latente geral de que o centro-interior e o sudoeste são apenas o relevo dialetal mais nítido. Poderá dizer-se, de acordo com os dados, que o centrointerior e o sudoeste são duas variedades que, como todas as personalidades dialetais do centro-sul, não deixam de se explicar por uma rede de parentescos profundamente

\footnotetext{
${ }^{7}$ Como refere Brissos (2014: 64), «As dialectological and historical studies put it, there are three main topics pertaining to the identity of Portuguese central-southern [...] dialects: a) they take their origin from the north of the country and developed in a part of the former medieval Islamic empire; b) they are fairly homogeneous, containing two very distinct varieties / subdialects; c) they form the basis of standard Portuguese» (vejam-se justificação e referências ibid.). A unidade deve-se a um natural processo de homogeneização linguística ocorrido na sequência da colonização linguística a que o sul de Portugal foi sujeito durante a Reconquista Cristã (i.e. a extensão do domínio cristão galego-português vindo do Norte, a área de origem do reino, para Sul). Colonos de diversa origem, em terra de falantes de outras línguas (sobretudo árabe), nivelaram a sua linguagem, processo reforçado pelo relevo pacífico do sul, ao contrário do do norte (um relevo mais pacífico proporciona comunicações fáceis, ao passo que um relevo acidentado favorece a correspondente compartimentação etnográfica e linguística). Esse processo de homogeneização é, fundamentalmente, um processo de koinê (Castro, 2006: 151).

${ }^{8}$ Nos referidos mapas apresentamos apenas os resultados cartográficos dos dados acústicos de Brissos; para a consulta dos valores $\mathrm{Hz}$ que estão por trás daquela cartografia (i.e. os dados resultantes da análise acústica), remetemos para a consulta da obra.
} 
dispersos pela macro-área a que pertencem, tanto ao nível dos seus traços dialetais principais como dos outros.

f) A existência desse fundo latente comum de que ressaltam as personalidades dialetais do centro-interior e do sudoeste faz supor que os fenómenos linguísticos que as compõem tenham uma base antiga, e os textos medievais comprovam-no. O único corpus significativo de documentos antigos produzidos no sueste da Beira (i.e. na metade Norte da variedade do centro-interior) que se conhece atesta a monotongação do ditongo [eic] (grafado <ei>, como em leite, sapateiro), fenómeno característico do centro-sul do país (Cintra, 1983a; Segura, 2013), já no séc. XIV (Brissos, 2012: 299-304). Ora, devido à sua contextualização própria, o fenómeno da palatalização de /a/ (que é despoletado por esse ditongo, monotongado ou não: cf. acima ponto (ii) da citação de Segura, 2013: 102103) é necessariamente anterior à monotongação de [ei], e por isso já se verificava no séc. XIV (veja-se outro argumento, menos substancial, a favor dessa conclusão em Brissos, 2012: 495-496). Da mesma forma, o facto de as vogais resultantes da palatalização de /a/ não velarizarem (Brissos, 2012: 55) mostra que o fenómeno da velarização de /e/ é anterior ao da palatalização de /a/ - e, por isso, também já existia no séc. XIV. Tanto a velarização de /e/ como a palatalização de /a/ são dos fenómenos mais marcados da região; serão mesmo, de resto, os fenómenos mais marcados da lista tradicional de traços que formam a chamada variedade da Beira Baixa e Alto Alentejo. Assim, a verificação da sua existência já no séc. XIV tem lições muito diretas para a cronologia dos outros fenómenos daquela lista; como Brissos (2012: 498) refere, «Se [a existência já no séc. XIV] se pode constatar para fenómenos que apresentam discrepâncias regionais significativas (sobretudo as velarizações, que excluem mesmo certas zonas), não é difícil supor, para fenómenos como as palatalizações de $u$ e $o u / o i$, que se verificam em toda a região, uma existência já naquela época». Isso será até necessário, dado que os fenómenos vocálicos do centro-interior têm, como já vimos, um nexo comum.

O vocalismo tónico do centro-interior depende, portanto, de um nexo comum já antigo do centro-sul do país. Mas quando se formou esse nexo? E de onde é originário? É exclusivamente português? Se sim, de que parte na metade meridional dos dialetos portugueses provém, se é que provém de algum lado em especial? E como se desenrolou o processo linguístico 
em si, i.e. que vogal(is) está(ão) na sua base? O estudo da fronteira Portugal-Espanha no sueste da Beira - a fronteira, grosso modo, entre o distrito de Castelo Branco e parte da província espanhola de Cáceres - providencia resultados fundamentais para a compreensão da génese do vocalismo tónico do centro-interior e, por isso, também da génese dos dialetos do centrosul. Por três razões:

a) A variedade do centro-interior, a que pertencem os falares/dialetos do sueste da Beira, tem, como refere Segura (2013: 103), «um marcado caráter arcaizante, que se manifesta sobretudo na conservação, em algumas localidades, de sons consonânticos que desapareceram há séculos de qualquer outro dialeto português, como a africada palatal

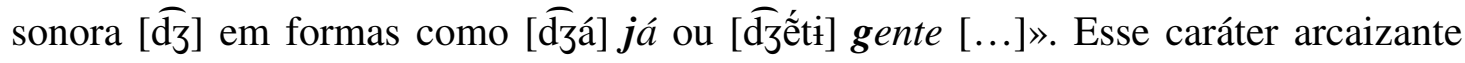
(incluindo a africada palatal sonora) é registado também por Brissos (2012: passim, esp. 486) para o sueste beirão em particular, dentro do qual destaca precisamente, no que não é de estranhar, a zona de fronteira como a mais conservadora (Brissos, 2012: 485-486). $\mathrm{Na}$ fronteira do sueste da Beira com Espanha estão, portanto, dialetos muito conservadores, que são normalmente os melhores para averiguar questões de história da língua.

b) Nos falares espanhóis vizinhos, os fenómenos vocálicos do centro-interior português não têm sido registados, como já Cintra (1983a: 156, n. 56) referia: «O fenómeno da palatalização [de /u/], assim como as outras alterações do sistema vocálico, é totalmente desconhecido dos dialectos espanhóis que se encontram do outro lado da raia.» Autores recentes como Montero Curiel (2006: 33) têm comprovado a observação para o lado de lá da fronteira em geral. Existe, pois, um clash fronteiriço que sugere uma origem portuguesa do vocalismo tónico idiossincrático do centro-sul.

c) Cintra (1983a: 156, n. 56) refere outro aspeto decisivo: os fenómenos vocálicos destacados do centro-interior/centro-sul desaparecem ou abrandam em direção à raia do sueste da Beira:

Os pontos [do Atlas Lingüístico de la Península Ibérica, em cujos dados o autor baseia o seu estudo] onde observámos a palatalização, mais ou menos acentuada do u [NB: considerado pelo autor o fenómeno basilar das variedades do centro-interior e do ocidente algarvio, e o que utiliza para a sua delimitação geográfica] são: [Reguengo (conc. de Portalegre), Belver (conc. de Mação), Montalvão (conc. de Nisa, «muito acentuada; poderia indicar-se como centro da região»), Alcains (conc. de Castelo Branco), Monsanto (conc. de Idanha-a-Nova), Oleiros, 
Ourondo (conc. da Covilhã)]. Curiosamente [a palatalização de /u/] já não se regista no Rosmaninhal, conc. de Idanha-a-Nova, junto da fronteira com Espanha [...]; julguei preferível não considerar este facto no mapa. Mas é provável que num mapa mais pormenorizado se tenha de suprimir uma zona vizinha da fronteira [...].

Brissos (2012) comprova, de facto, um abrandamento geral da variedade do centro-interior na direção da raia do sueste beirão (i.e. regista menos, em quantidade ou qualidade, o vocalismo destacado do centro-interior na zona de fronteira referida), apesar de atestar (claramente) a palatalização de /u/ no Rosmaninhal (Brissos, 2012: 75-76 e 481 ss.).

O problema dos dados de Cintra e Brissos é que não dependem de uma rede de pontos de inquérito verdadeiramente densa, pelo que se impõe o estudo do vocalismo de uma boa cobertura de pontos localizados na fronteira para averiguar o modo como efetivamente se dá a referida perda de intensidade dialetal em direção ao extremo linguístico geográfico da variedade. Se se comprovar esse abrandamento numa das áreas dialetais portuguesas mais conservadoras, fica claro que devemos procurar a origem do vocalismo distintivo do centrointerior, e as tendências mais gerais de que ele depende, não só longe da raia como dentro do quadro da história do português. Para além disso - e talvez mais importante - , se os fenómenos não abrandarem todos do mesmo modo na fronteira (i.e. se alguns sobreviverem, no todo ou em parte), podemos tentar estabelecer uma ordem, cronológica e de importância, de cada um dos fenómenos na verdadeira revolução que eles representam no vocalismo tónico. Estamos, com efeito, a falar de uma área extremamente conservadora: qualquer discordância em relação ao standard da variedade do centro-interior representará, por princípio, um traço de segunda ordem da mesma.

\subsection{Metodologia}

Os materiais do Frontespo proporcionam-nos uma cobertura da zona raiana do sueste da Beira que é suficiente para permitir um esclarecimento dos dois aspetos referidos no fim do subponto anterior. Às quatro localidades iniciais compreendidas nas zonas 6 e 7 (mapa 1, Anexo), foram adicionadas outras quatro, onde foi realizada uma campanha de inquéritos extra, precisamente com o fim de melhor cobrir a área raiana de uma região dialetal de interesse elevado. Tendo em conta que se trata de uma região extremamente deprimida demograficamente, as oito localidades, todas pequenas aldeias de, quando muito, poucas centenas de habitantes, representam a quase totalidade das variedades localizadas, dentro do 
concelho de Idanha-a-Nova, a menos de 15 quilómetros da fronteira (o limiar do Frontespo). Ou seja, o que de mais raiano se encontra no sueste da Beira.

Dessa seleção resultou um corpus com as oito localidades indicadas no mapa 5 (Anexo), a que correspondem cerca de 52 horas de gravação, registadas numa média de 2 dias por localidade. Foram entrevistados 46 informantes no total, assim divididos por género e escalões etários:

\begin{tabular}{|l|c|c|c|c|c|c|c|c|}
\hline \multirow{2}{*}{ Localidade } & \multicolumn{2}{|c|}{$\begin{array}{c}\text { Escalão 1 } \\
\text { (até 50 anos) }\end{array}$} & \multicolumn{2}{c|}{$\begin{array}{c}\text { Escalão 2 } \\
(50-75 \text { anos })\end{array}$} & \multicolumn{2}{c|}{$\begin{array}{c}\text { Escalão 3 } \\
\text { (mais de 75 anos) }\end{array}$} & \multicolumn{2}{c|}{$\begin{array}{c}\text { Total de } \\
\text { informantes }\end{array}$} \\
\cline { 2 - 10 } & Homem & Mulher & Homem & Mulher & Homem & Mulher & Homem & Mulher \\
\hline $\begin{array}{l}\text { Malpica do } \\
\text { Tejo }\end{array}$ & - & 1 & 1 & 1 & 2 & 3 & 3 & 5 \\
\hline $\begin{array}{l}\text { Monforte da } \\
\text { Beira }\end{array}$ & 1 & - & 1 & 1 & 2 & 1 & 4 & 2 \\
\hline Rosmaninhal & - & - & 1 & - & 3 & 2 & 4 & 2 \\
\hline Segura & - & - & 1 & 1 & 1 & 1 & 2 & 2 \\
\hline $\begin{array}{l}\text { Salvaterra } \\
\text { do Extremo }\end{array}$ & - & - & 1 & 1 & 3 & - & 4 & 1 \\
\hline Toulões & - & - & - & - & 1 & 4 & 1 & 4 \\
\hline Torre & - & - & - & - & 2 & 1 & 2 & 1 \\
\hline Monfortinho & - & - & 1 & 2 & 5 & 1 & 6 & 3 \\
\hline
\end{tabular}

De acordo com o tipo demográfico do interior português (região rural e extremamente deprimida, onde só os idosos vão permanecendo) e o conhecimento exigido para as respostas ao questionário, o perfil de informante utilizado tem, por defeito, escolarização baixa. Assim, no escalão 3 predominam os informantes analfabetos ou com estudos primários (completos ou incompletos), enquanto nos escalões 1 e 2 predominam os informantes com estudos primários ou, menos, secundários (não foi entrevistado nenhum informante licenciado). Esta seleção de informantes com um perfil linguístico conservador está totalmente de acordo com o objetivo de documentar a linguagem dialetal das áreas analisadas. De acordo com o mesmo objetivo, os informantes inquiridos passaram um mínimo de tempo fora das localidades respetivas, o que, no interior português, não é fácil de encontrar atualmente; a emigração, mesmo que temporária, é frequente há já algumas gerações. 
A campanha extra de inquéritos, de que resultaram os dados de Rosmaninhal, Toulões, Torre e Monfortinho, compreendeu quase apenas informantes com o perfil mais conservador (poucos estudos, se algum), pois o objetivo era precisamente aceder ao estado de língua mais conservador da região para esclarecer questões como as que nos ocupam neste trabalho. Nas outras localidades, a falta de informantes do escalão 1 deve-se à já referida depressão demográfica do interior.

Neste estudo apresentamos o resultado da análise percetiva dos dados realizada por um investigador que esteve no campo e, por isso, não se cinge apenas aos dados gravados, utilizando também os apontamentos resultantes do confronto direto e próximo com a linguagem em estudo durante vários dias (incluindo informantes não gravados).

\subsection{Resultados}

Os resultados mostram duas ordens de fenómenos bem distanciadas entre si: os fenómenos gerais e os não gerais, ou, mais precisamente, os fenómenos que ocorrem em todos os pontos de inquérito estudados e os que ocorrem em poucos ou só em um. Os primeiros são apresentados no mapa 6 e os segundos no mapa 7 (ambos no Anexo adiante).

Tornam-se evidentes ainda outros quatro aspetos importantes:

a) O deslocamento em cadeia total só existe numa das localidades consideradas, mas existe. Por sua vez, a existência do fenómeno na vogal /i/ não pôde ser comprovada, mas esse fenómeno é esporádico em todo o centro-interior (ao contrário do barlavento algarvio). A notar ainda sobre este aspeto que o deslocamento em cadeia ocorre mais no género feminino, apesar de não ser exclusivo desse género.

b) A velarização de /E/ normativo não está registada na região, o que concorda com os dados de Brissos (2012: 61), que só a atestam na metade ocidental do distrito de Castelo Branco.

c) Fica comprovada a hipótese do abrandamento dos caracteres dialetais destacados do centro-interior em relação à fronteira, corroborando as já referidas indicações de Cintra (1983a: 156, n. 56) e Brissos (2012: 481 ss.). Veja-se por exemplo o mapa 8 (Anexo), que sistematiza os dados de Brissos (2012) relativos às vogais anteriores não-altas. $\mathrm{Na}$ distribuição dos fenómenos respeitantes a essas vogais, é patente a perda de dimensão em direção à fronteira: na metade ocidental do sueste beirão existe a velarização dos 
dois $e$ 's e na metade oriental só a de um e, que desaparece na zona raiana propriamente dita, onde quase não existem fenómenos respeitantes às duas vogais consideradas.

d) As indicações de Cintra ficam, porém, corroboradas apenas parcialmente, pois, como se vê no mapa 6 , a fronteira pertence indubitavelmente à variedade do centro-interior apenas pertence num grau inferior.

As consequências destes factos para as questões referidas em $\mathbf{2 . 1}$ são importantes. Vêlas-emos a seguir.

\section{Conclusão}

Na sequência do que vimos em 2.1, o estudo do vocalismo na fronteira do sueste da Beira com Espanha é importante por duas razões fundamentais: verificar se os dialetos/falares locais pertencem de facto à variedade do centro-interior; e se, mesmo pertencendo, existe realmente um abrandamento dos caracteres essenciais dessa variedade na região fronteiriça. As informações da literatura permitem colocar essas hipóteses, mas com base em dados muito escassos sobre a fronteira propriamente dita (e.g. Cintra, 1983a e Brissos, 2012, que dispõem de uma cobertura reduzida da zona).

A resolução dessas duas questões tem, por sua vez, implicações decisivas para o entendimento da génese e constituição dos dialetos portugueses meridionais, na medida em que, como estudos recentes têm mostrado, a variedade do centro-interior, apesar de ser uma região destacada no panorama dialetal português, não representa mais do que uma exponenciação de um perfil latente no centro-sul português.

Os dados do Frontespo permitiram de facto resolver as duas questões referidas, sendo possível afirmar que:

a) a variedade dialetal do centro-interior português não desaparece na fronteira, mas

b) perde uma parte importante da sua força aí; apenas três dos seus traços mais destacados lá sobrevivem, todos palatalizações: de /u/ e /a/ tónicos e do antigo ditongo [oun], tónico ou átono.

c) A existência de divergências nítidas na distribuição de fenómenos linguísticos componentes da variedade do centro-interior, em conjugação com o facto de a raia do sueste da Beira ser uma zona dialetal extremamente conservadora, aponta para que haja duas ordens históricas de fenómenos: fenómenos que poderemos considerar originais — os que têm uma presença geral na região — e fenómenos derivados desses — os que 
têm uma presença reduzida. É pelos (poucos) primeiros que as teorias explicativas da origem da variedade devem começar, o que, tendo em conta as dificuldades inerentes à reconstrução de estados de língua tão pretéritos, não deixa de ser uma ajuda importante.

d) Por sua vez, a origem da variedade do centro-interior deve ser procurada já no quadro histórico da língua portuguesa (independentemente de eventuais influências anteriores ou posteriores), pois não só (i) a zona raiana do sueste beirão pertence à variedade referida e (ii) é uma área dialetal conservadora, como (iii) os caracteres dialetais tidos como típicos do centro-interior não se verificam no lado espanhol da fronteira. Está aí outra ajuda importante para o discernimento da origem do vocalismo do centro-interior,

e) questão que, por outro lado, deve considerar toda a formação dos dialetos centromeridionais, na medida em que a variedade do centro-interior é tão-só um cúmulo de um relevo dialetal essencialmente coerente do centro-sul do país, de que o português padrão diverge. O contraste com os dialetos setentrionais é, por isso, maior do que pensamos tradicionalmente,

f) tal como a divergência com a variedade normativa. Aí cumpre perceber porque é que o português padrão diverge tão incisivamente da área dialetal em que está filiado há séculos. Por conservadorismo da sua origem nortenha? Ou por não estar assim tão integrado no sul do país quanto isso?

É para resolver ou tentar melhorar questões como estas que projetos do tipo do Frontespo são necessários na fase atual da dialetologia portuguesa. Poderá dizer-se que, depois de uma primeira fase dos estudos dialetais portugueses em que se incidiu na recolha de dados micro (i.e. estudos de localidades/falares específicos: trabalhos de campo de Leite de Vasconcelos, teses de licenciatura orientadas por Paiva Boléo e Lindley Cintra em, respetivamente, Coimbra e Lisboa) e de uma segunda fase, iniciada nos anos 1960', em que se incidiu numa visão macro (i.e. estudos de conjunto: propostas de classificação dialetal de Paiva Boléo e Lindley Cintra, recolhas do Atlas Linguístico-Etnográfico de Portugal e da Galiza), necessitamos agora de mais estudos micro para melhorar as visões de conjunto de que dispomos, quase intocadas, há décadas. Estudos micro que podem, naturalmente, incidir sobre dados a recolher ou sobre dados já recolhidos — veja-se o exemplo do Atlas LinguísticoEtnográfico de Portugal e da Galiza, cujos materiais, apesar de livres para consulta, se encontram na sua maioria inéditos. 
O Frontespo insere-se nesse perfil e os dados da secção 2 são um exemplo da validade e da necessidade desse tipo de abordagem. A abordagem metodológica e programática do Frontespo em concreto, que descrevemos detalhadamente na secção 1, é apenas um caminho possível, aqui registado para reflexão e eventual uso na constituição de projetos similares.

\section{Referências}

Álvarez Pérez, Xosé Afonso (2015) Presentación del proyecto Frontera Hispano-Portuguesa: Documentación Lingüística y Bibliográfica (FRONTESPO). Manuscrito, texto submetido.

Amante, $M^{a}$ de Fátima (2010) Local discursive strategies for the cultural construction of the border: the case of the Portuguese-Spanish border. Journal of Borderland Studies 25 (1), pp. 99-114.

Andrés Díaz, Ramón de (2007) Linguistic borders of the Western Peninsula. International Journal of the Sociology of Language 184, pp. 121-138.

Atlas Lingüístico de la Península Ibérica. Vol. I - Fonética. 1962, Madrid: Consejo Superior de Investigaciones Científicas.

Beswick, Jaine (2005) Linguistic homogeneity in Galician and Portuguese borderland communities. Estudios de Sociolingüística 6 (1), pp. 39-64.

Boléo, Manuel de Paiva \& Maria Helena Santos Silva (1974) O "Mapa dos Dialectos e Falares de Portugal Continental”. In Manuel de Paiva Boléo, Estudos de linguística portuguesa e românica. Vol. I - Dialectologia e história da língua, t. I. Coimbra: Universidade de Coimbra, pp. 321-352. (Trata-se da versão revista e aditada da publicação original: 1962, Boletim de Filologia XX, pp. 85-112.)

Boller, Fred (1995) Die Isoglossenstaffelung in der galicisch-portugiesisch-spanischen Kontaktzone und im Lombada-Aliste-Grenzgebiet. 2 vols, Kiel: Westensee-Verl.

Brissos, Fernando (2012) Linguagem do sueste da Beira no tempo e no espaço. Lisboa: Centro de Linguística da Universidade de Lisboa.

- - (2014) New insights into Portuguese central-southern dialects: understanding their present and past forms through acoustic data from stressed vowels. Journal of Portuguese Linguistics 13 (1), pp. 63-115. 
(2015) Dialectos portugueses do Centro-Sul: corpus de fenómenos e revisão do problema da (des)unidade. Zeitschrift für romanische Philologie 131 (4), pp. 999-1041. Carrasco González, Juan (1996) Hablas y dialectos portugueses o galaico-portugueses en Extremadura (Parte I: grupos dialectales. Clasificación de las hablas de Jálama). Anuario de Estudios Filológicos XIX, pp. 135-148.

(1997) Hablas y dialectos portugueses o galaico-portugueses en Extremadura (Parte II y Última: otras hablas fronterizas; conclusiones). Anuario de Estudios Filológicos XX, pp. 61-79.

Castro, Ivo (2006) Introdução à história do português. 2. ${ }^{a}$ edição revista e muito ampliada, Lisboa: Colibri.

Cintra, Luís Lindley (1983a) Nova proposta de classificação dos dialectos galego-portugueses. In Luís Lindley Cintra, Estudos de dialectologia portuguesa. Lisboa: Sá da Costa, pp. 119-163. (Primeira publicação, 1971: Boletim de Filologia XXII, pp. 81-116.)

(1983b) Os ditongos decrescentes ou e ei: esquema de um estudo sincrónico e diacrónico. In Luís Lindley Cintra, Estudos de dialectologia portuguesa. Lisboa: Sá da Costa, pp. 35-54. (Primeira publicação, 1970: Anais do Primeiro Simpósio de Filologia Românica (1958), Rio de Janeiro, pp. 115-134.)

Delgado-Martins, Maria Raquel (2002) Análise acústica das vogais tónicas do português. In Maria Raquel Delgado-Martins, Fonética do português: trinta anos de investigação. Lisboa: Caminho, pp. 41-52. (Primeira publicação, 1973: Boletim de Filologia XXII, pp. 303-314.)

Escudero, Paola, Paul Boersma, Andréia Schurt Rauber \& Ricardo A. H. Bion (2009) A crossdialect acoustic description of vowels: Brazilian and European Portuguese. Journal of the Acoustical Society of America 126 (3), pp. 1379-1393.

Gargallo Gil, José Enrique (2011) Fronteras romances en la Península Ibérica. In Ramón de Andrés Díaz (ed.) Lengua, ciencia y fronteras. Uviéu (Oviedo): Trabe, pp. 35-68.

Ferreira, Manuela Barros \& José Antonio González Salgado (orgs.) (2015) Língua e cultura na fronteira norte-sul: bibliografia. Campo Arqueológico de Mértola, http://hdl.handle.net/10400.26/8972.

Frontera Hispano-Portuguesa: Documentación Linguística y Bibliográfica (FRONTESPO), página web: http://www.frontespo.org/. 
Maia, Clarinda de Azevedo (1977) Os falares fronteiriços do concelho do Sabugal e da vizinha região de Xalma e Alamedilla. Coimbra: Universidade de Coimbra.

- (2001) Fronteras del español: aspectos históricos y sociolingüísticos del contacto con el portugués en la frontera territorial. In II Congreso Internacional de la Lengua Española: el español en la sociedad de la información. Valladolid: Instituto Cervantes, Centro Virtual Cervantes.

Matias, Maria de Fátima de Rezende Fernandes (1984) Bilinguismo e níveis sociolinguísticos numa região luso-espanhola (concelhos de Alandroal, Campo Maior, Elvas e Olivença). Coimbra: Instituto de Língua e Literatura Portuguesas, Faculdade de Letras da Universidade de Coimbra.

(2001) A agonia do português em Olivença. Revista de Filología Románica 18, pp. 159-170.

Merlan, Aurelia (2009) El mirandés: situación sociolingüística de una lengua minoritaria en la zona fronteriza portugueso-española. Uviéu (Oviedo): Academia de la Llingua Asturiana.

Ossenkop, Christina (2013) Spanisch-portugiesischer Sprachkontakt in der Extremadura am Beispiel der Gemeinden Cedillo, Valencia de Alcántara und La Codosera. Wilhelmsfeld: Gottfried Egert Verlag.

Raposo, Eduardo Paiva, Maria Fernanda Bacelar do Nascimento, Maria Antónia Mota, Luísa Segura \& Amália Mendes (orgs.) (2013) Gramática do português, vol. I. Lisboa: Fundação Calouste Gulbenkian.

Santos, Maria José de Moura (1967) Os falares fronteiriços de Trás-os-Montes. Coimbra: Universidade de Coimbra.

Segura, Luísa \& João Saramago (2001) Variedades dialectais portuguesas. In Maria Helena Mira Mateus (coord.) Caminhos do português. Lisboa: Biblioteca Nacional, pp. 221240.

Segura da Cruz, Mª Luísa (1987) A fronteira dialectal do Barlavento do Algarve. Dissertação em linguística portuguesa para acesso à categoria de investigador auxiliar (equivalente a doutoramento), Universidade de Lisboa. 
- (2013) Variedades dialetais do português europeu. In Eduardo Paiva Raposo, Maria Fernanda Bacelar do Nascimento, Maria Antónia Mota, Luísa Segura \& Amália Mendes (orgs.) Gramática do português, vol. I. Lisboa: Fundação Calouste Gulbenkian, pp. 85142.

Teyssier, Paul (2001) História da língua portuguesa. Tradução portuguesa de Celso Cunha, 8. a edição, Lisboa: Sá da Costa. (Edição original: Histoire de la langue portugaise, 1980, Presses Universitaires de France, in coleção «Que sais-je?»)

Vasconcelos, José Leite de (1893) Carta dialectologica do continente português. In Manuel Ferreira-Deusdado, Chorographia de Portugal. Lisboa: Guillard, Aillaud \& C.ia, pp. 15-16. (Separata: Vasconcelos, José Leite de (1897) Mappa Dialectologico do Continente Português (precedido de uma classificação summaria das linguas por A. $R$. Gonçalves Vianna). Lisboa: Guillard, Aillaud \& C. ${ }^{\text {ia }}$.) — Reedição com alterações: Vasconcelos, José Leite (1929) Mapa dialectológico do continente português. In José Leite de Vasconcelos, Opúsculos. Vol. IV - Filologia (Parte II). Coimbra: Imprensa da Universidade, pp. 791-796.

(1901) Esquisse d'une dialectologie portugaise. Tese de doutoramento apresentada à Faculdade de Letras da Universidade de Paris. Paris: Aillaud. (2. ${ }^{a}$ edição com aditamentos e correcções do autor, preparada, com base no exemplar conservado no Museu Etnológico Dr. Leite de Vasconcellos, por Maria Adelaide Valle Cintra, 1970, Lisboa: Centro de Estudos Filológicos. 3. ${ }^{a}$ edição, fac-simile da anterior, 1987, Lisboa: Centro de Linguística da Universidade de Lisboa.)

Vázquez Cuesta, Pilar \& Maria Albertina Mendes da Luz (1980) Estado actual do português na Península Ibérica. In Pilar Vázquez Cuesta \& Maria Albertina Mendes da Luz, Gramática da língua portuguesa. Tradução de Ana Maria Brito e Gabriela de Matos a partir da 3. ${ }^{a}$ edição corrigida e aumentada (1971), Lisboa: Edições 70, pp. 52-78. 


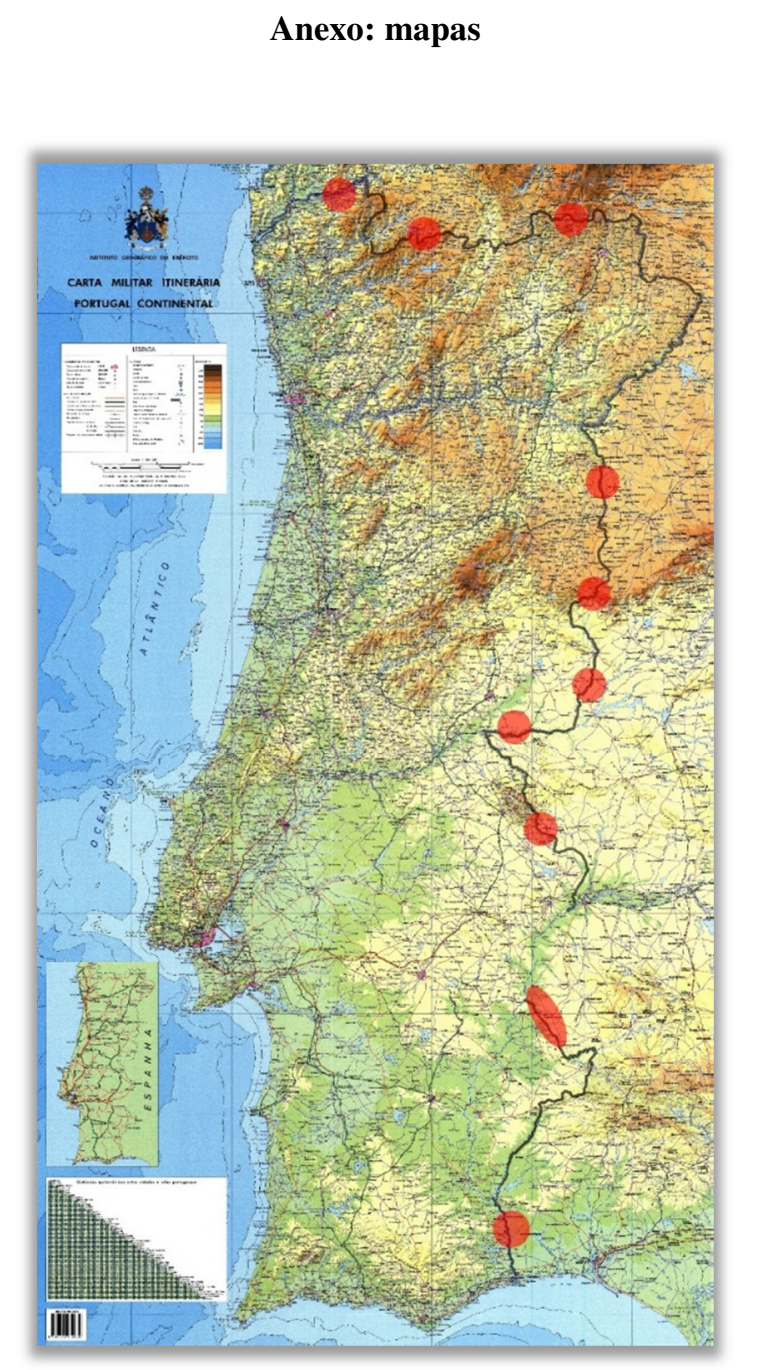

Mapa 1 - Zonas-alvo do corpus oral do Frontespo, 1. ${ }^{\mathrm{a}}$ fase

Legenda: de Oeste para Este e de Norte para Sul: Zona 1: Pontevedra / Viana do Castelo. Zona 2: Ourense / Vila Real. Zona 3: Zamora / Bragança. Zona 4: Salamanca / Guarda. Zona 5: Salamanca / Guarda. Zona 6: Cáceres / Castelo Branco. Zona 7: Cáceres / Castelo Branco. Zona 8: Badajoz / Portalegre. Zona 9: Badajoz / Évora-Beja. Zona 10: Huelva / Faro. 


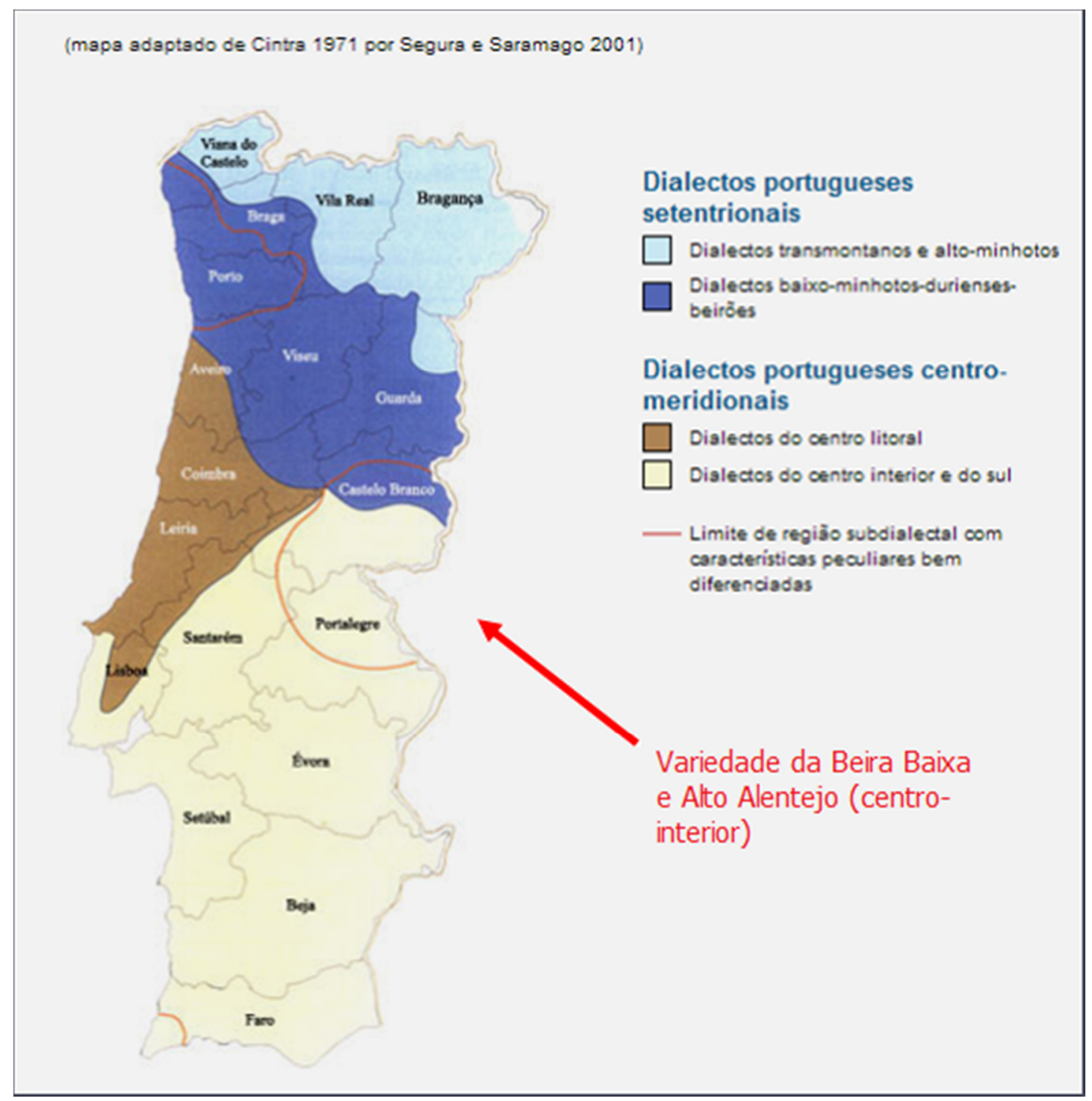

Mapa 2 - Proposta de classificação dos dialetos portugueses de Lindley Cintra 


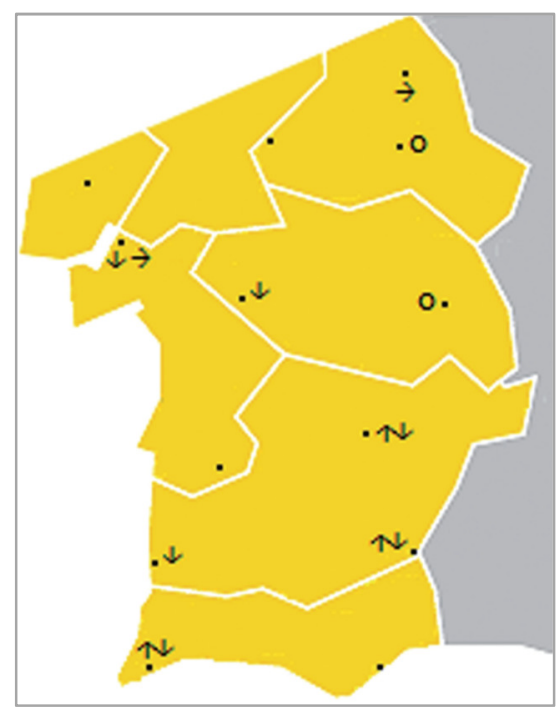

Mapa 3 - Fenómenos respeitantes à qualidade vocálica de /e/ e /ع/

Legenda:

tónicos do português padrão no centro-sul português (Brissos, 2014)

$\uparrow \downarrow=$ pontos de inquérito com sistemas vocálicos com (i) destacada abertura/fechamento de /e ع/ do português padrão e (ii) a vogal /æ/. (Um e outro fenómenos ocorrem sempre na mesma contextualização, que é a descrita pela literatura para o barlavento algarvio, de onde o traço é, de acordo com a literatura, característico: cf. Segura (2013: 104-105). Esses fenómenos contextuais têm contudo consequências fonológicas no subsistema das vogais anteriores não-altas do barlavento e dos outros locais que o partilham, processo esse que é parte integrante do deslocamento em cadeia do vocalismo tónico que já referimos; veja-se a justificação completa da interpretação fonológica em Segura (1987: 342 ss.).)

$\downarrow=$ pontos de inquérito com sistemas vocálicos com destacada abertura/fechamento de /ع/ do padrão (sempre de acordo com a contextualização do barlavento algarvio) mas sem a vogal /æ/. (A mesma abertura/fechamento de / $\varepsilon /$ que pode ser encontrada nos locais indicados ocorre igualmente em todos os restantes pontos de inquérito, mas aí sem resultar num timbre vocálico específico.)

$\rightarrow=$ pontos de inquérito com velarização de /e/ que não resulta da monotongação do antigo ditongo [ei] (traço característico do centro-interior).

$\mathbf{O}=$ pontos de inquérito com arredondamento das duas vogais anteriores não altas: /e $\varepsilon /$ (traço relacionado com a velarização dessas vogais: cf. Brissos, 2014: 86-89). 


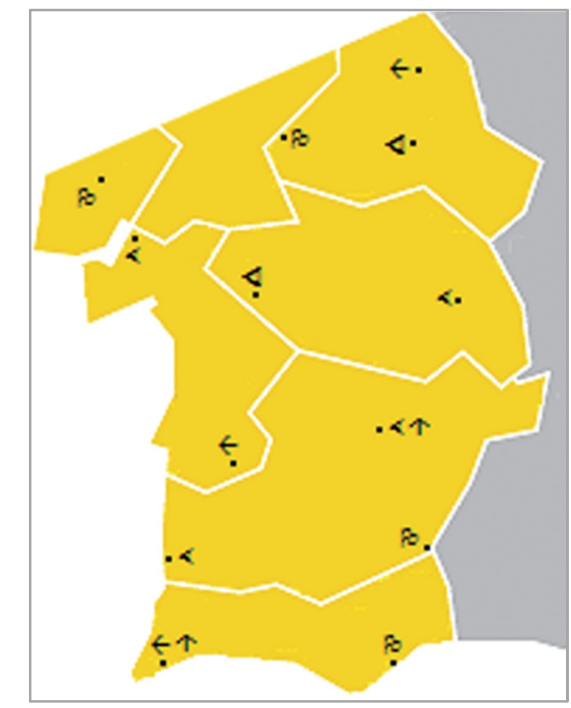

Mapa 4 - Fenómenos respeitantes à qualidade vocálica de /o/ e /u/ tónicos do português padrão no centro-sul português (adaptação de Brissos, 2014)

\section{Legenda:}

$\uparrow=$ pontos de inquérito com /ọ/ (traço característico, de acordo com a literatura, do barlavento algarvio).

$\leftarrow=$ pontos de inquérito com / $\mathrm{u} /$ (i.e. não existência de /u/; traço característico do barlavento algarvio e do centro-interior).

pe = pontos de inquérito em que /u/ é a vogal mais recuada do sistema.

$\varangle=$ pontos de inquérito em que /u/ é menos recuado do que as outras duas vogais posteriores (/o/ e /o/ ou /o/s).

$\triangleleft$ = pontos de inquérito em que /u/ é menos recuado do que /o/, mas mais recuado do que /っ/ (i.e. a outra vogal posterior).

(Verifica-se portanto uma tendência geral do centro-sul para o avanço articulatório de $u$ tónico, i.e. a vogal correspondente a /u/ tónico do português padrão não reside normalmente na posição mais recuada do sistema, podendo mesmo chegar à vogal central $/ \mathfrak{u} /$ bem fora das zonas a que é tradicionalmente indexado (sudoeste e centro-interior). No português padrão, /u/ tem sido inquestionavelmente localizado na posição mais recuada do sistema: cf. Delgado-Martins (2002) e Escudero et al. (2009).) 


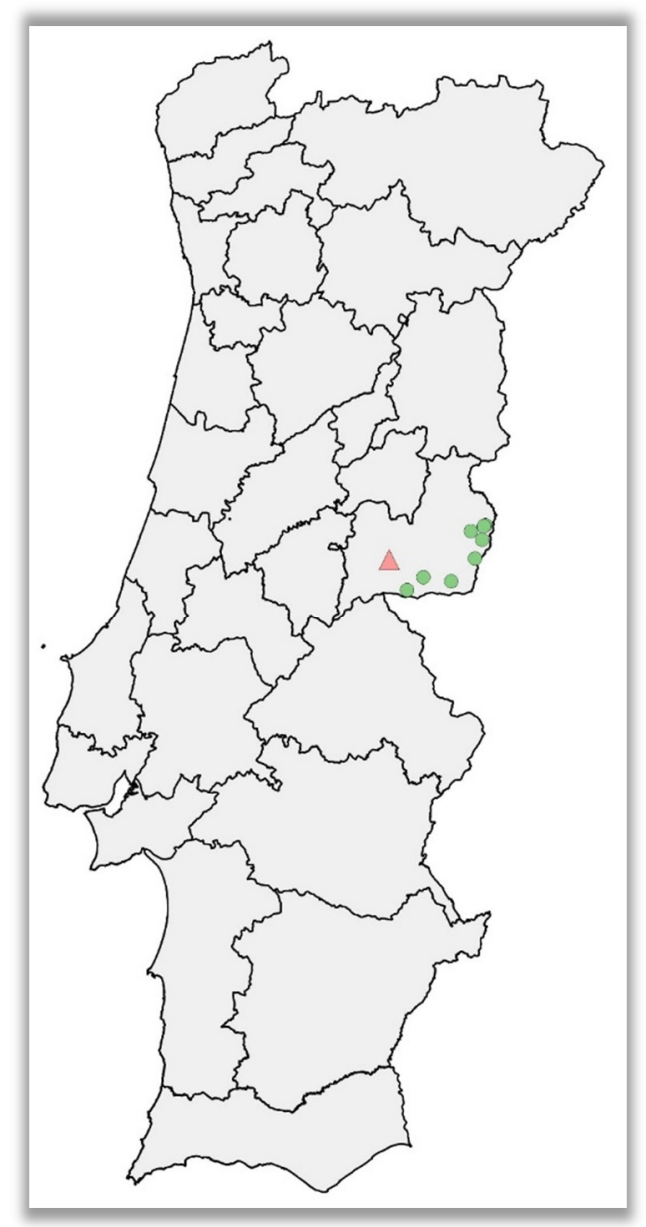

Mapa 5 - Rede de localidades inquiridas para este estudo

Legenda:

- localidades inquiridas (de Sul para Norte e Oeste para Este): Malpica do Tejo, Monforte da Beira, Rosmaninhal, Segura, Salvaterra do Extremo, Toulões, Torre, Monfortinho.

$\Delta=$ Castelo Branco.

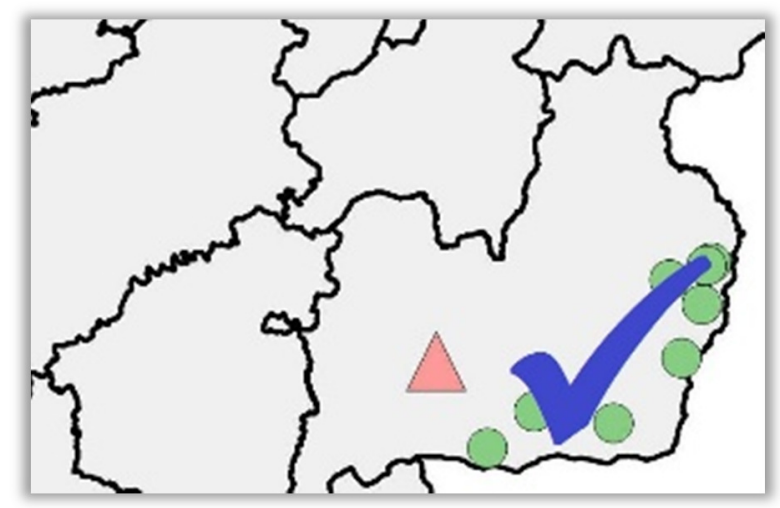

Mapa 6 - Fenómenos gerais na região analisada

Legenda: os fenómenos são as palatalizações de /u/, do antigo ditongo [oun] e de /a/ (esta contextual, como se espera na região). 


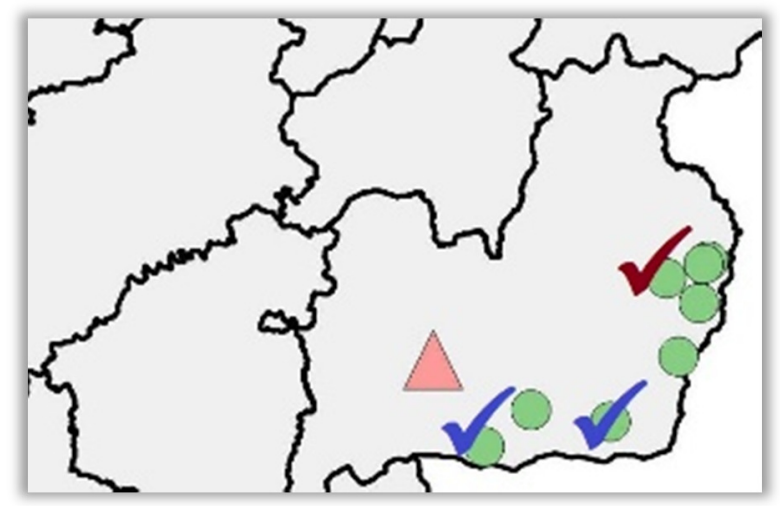

Mapa 7 - Fenómenos não gerais na região analisada

Legenda:

$\checkmark$ Velarização de /e/.

$\checkmark$ Deslocamento em cadeia do vocalismo tónico (não comprovado absolutamente para a vogal /i/; inclui a velarização de /e/, mas não a de /ع/).

NB: Fenómenos componentes do deslocamento em cadeia que ocorrem de forma isolada numa dada localidade (e.g. abertura de / / /) não são indicados, uma vez que o nosso propósito aqui é ressaltar os fenómenos principais do vocalismo tónico do centro-interior. O contraste claro de Toulões, em que o deslocamento em cadeia se verifica em todo o sistema, com o resto da rede proporciona essa cartografagem mais fácil.

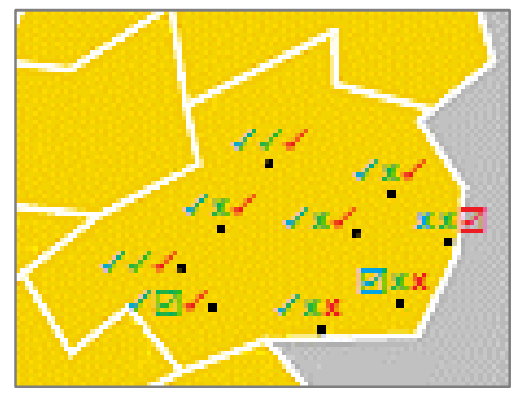

Mapa 8 - Fenómenos relativos às vogais /e/ e /ع/ tónicas do português padrão no sueste da Beira (dados de Brissos, 2012)

Legenda:

1. Fenómenos linguísticos: velarização de /e/ tónico; velarização de /E/ tónico; abertura de /ع/.

2. Simbologia: $\checkmark=$ fenómeno verificado. $\square=$ fenómeno verificado parcialmente (e.g. apenas em um informante, ou em apenas alguns contextos fonéticos). $\mathbf{x}=$ negação da existência do fenómeno.

NB: As três localidades junto à fronteira também estão representadas no corpus do presente trabalho: Malpica do Tejo, Rosmaninhal e Salvaterra do Extremo. 